\title{
Plasma lipoprotein(a) concentration and phenotypes in diabetes mellitus
}

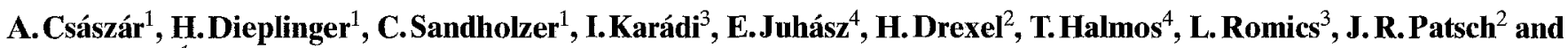 \\ G. Utermann ${ }^{1}$ \\ ${ }^{1}$ Institute of Medical Biology and Human Genetics, and \\ ${ }^{2}$ Department of Medicine, University of Innsbruck, Austria \\ ${ }^{3}$ Third Department of Medicine, Semmelweis Medical University \\ ${ }^{4}$ Department of Medicine, Korányi Institute, Budapest, Hungary
}

\begin{abstract}
Summary. Patients with Type 1 (insulin-dependent) and Type 2 (non-insulin-dependent) diabetes mellitus are at increased risk of developing atherosclerotic vascular diseases. A variety of lipoprotein abnormalities have been described as being associated with this increased risk. In this study, apo(a) isoform frequencies and lipoprotein(a) $[\mathrm{Lp}(\mathrm{a})]$ concentrations were determined in Type 1 and Type 2 diabetic patients in order to investigate a possible contribution of $\mathrm{Lp}(\mathrm{a})$ to the increased risk for atherosclerosis in diabetes. No significant differences in plasma $\mathrm{Lp}$ (a) concentrations were found in two ethnically different populations (Austrians from the province of Tyrol and Hungarians from Budapest) in either type of diabetes when compared to respective con-
\end{abstract}

trol groups (91 Type 1 and 112 Type 2 diabetic patients vs 202 control subjects in the Hungarian study and 44 Type 1 diabetic and 44 Type 2 diabetic vs 125 control subjects in the Austrian study). There were also no significant apo(a) isoform frequency differences between both patient groups and control subjects in the two study groups. These data, obtained from two large ethnically different populations, provide no evidence of a contribution of $L p(a)$ to the increased risk for atherosclerosis in diabetes.

Key words: Diabetes mellitus, lipoprotein(a), apo(a) isoforms.
The well-known high rate of cardiovascular morbidity and mortality in diabetic patients indicates the existence of risk factors related to the disease, which may enhance the susceptibility to atherosclerosis [1]. Several studies indicate that lipoprotein alterations found in long-term diabetes mellitus contribute to the development of late macrovascular atherosclerotic complications. Careful analysis of lipoprotein metabolism did not reveal any pathological changes specific for diabetes. Poor metabolic control per se does not fully explain the lipoprotein abnormalities in all types of diabetic patients $[2,3]$. It has been postulated that diabetic dyslipidaemia contributes to the atheroscelerotic process in the same way as in other, nondiabetic patients [4].

In this study we investigated whether diabetes has an effect on the atherogenic lipoprotein(a) (Lp(a)). Numerous case-control studies have provided evidence for the significance of elevated Lp(a) plasma concentrations as a risk factor for atherosclerotic diseases [5-7]. Therefore, diabetes-induced elevations of $\mathrm{Lp}(\mathrm{a})$ might contribute to the increased risk for coronary heart disease in the diabetic population. The atherogenicity of $\mathrm{Lp}(\mathrm{a})$ may be partly explained by its high affinity to glycosaminoglycans of the extracellular matrix [8], or alternatively, by its ability to interfere in vitro with the fibrinolytic cascade [9].

$\mathrm{Lp}(\mathrm{a})$ is a low-density lipoprotein (LDL)-like particle which carries the $\mathrm{Lp}(\mathrm{a})$-specific glycoprotein apo(a) [10-12]. Sequence comparisons as well as immunochemical investigations have demonstrated the high structural similarity between apo(a) and plasminogen [13-15]. Apo(a) exhibits a genetically determined size polymorphism. Six different genetic isoforms (designated $F, B, S_{1}, S_{2}$, $\mathrm{S}_{3}$ and $\mathrm{S}_{4}$ according to different electrophoretic mobilities), that vary in size from about $400 \mathrm{kD}$ to more than $800 \mathrm{kDa}$ were originally discovered [16]. Meanwhile, improved techniques at higher resolution have revealed more than 20 protein isoforms [17]. Quantitative Southern blotting and pulsed-field gel electrophoresis have shown that this polymorphism results from varying numbers of tandem kringle 4 repeats, leading to more than 19 different apo(a) alleles [18-21]. In the general population, the size of these isoforms is inversely related to the plasma concentration of $\mathrm{Lp}(\mathrm{a})$. Large isoforms are associated with low $\mathrm{Lp}(\mathrm{a})$ and small isoforms with high $\mathrm{Lp}(\mathrm{a})$ concentrations in plasma. In healthy Caucasians, roughly half of the variability in $\mathrm{Lp}(\mathrm{a})$ levels is attributed to the apo(a) size polymorphism [22]. 
Table 1. Lipid and lipoprotein plasma concentrations, laboratory data and clinical characterization (mean \pm SD) of Hungarian subjects

\begin{tabular}{|c|c|c|c|}
\hline & $\begin{array}{l}\text { Type } 1 \text { diabetic patients } \\
n=91\end{array}$ & $\begin{array}{l}\text { Type } 2 \text { diabetic patients } \\
n=112\end{array}$ & $\begin{array}{l}\text { Control subjects } \\
n=202\end{array}$ \\
\hline Cholesterol (mmol/l) & $5.7 \pm 2.0$ & $5.8 \pm 1.3$ & $5.6 \pm 1.1$ \\
\hline Triglycerides $(\mathrm{mmol} / \mathrm{l})$ & $2.3 \pm 4.0$ & $2.6 \pm 2.0$ & - \\
\hline $\mathrm{HDL}_{2}$ cholesterol $(\mathrm{mmol} / 1)$ & $0.3 \pm 0.2^{\mathrm{a}}$ & $0.2 \pm 0.1^{\mathrm{a}}$ & $0.3 \pm 0.1^{a}$ \\
\hline $\mathrm{HDL}_{3}$ cholesterol $(\mathrm{mmol} / \mathrm{l})$ & $1.0 \pm 0.4^{\mathrm{a}}$ & $0.8 \pm 0.3^{\mathrm{a}}$ & $0.8 \pm 0.2^{\mathrm{a}}$ \\
\hline LDL cholesterol (mmol/l) & $3.9 \pm 1.5$ & $4.2 \pm 1.2$ & - \\
\hline Lp(a) (quartiles: 25 th, 75 th) & 1.410 .5 & 1.511 .9 & $2.0 \quad 12.5$ \\
\hline Age of all subjects (years) & $41.5 \pm 15.1^{\mathrm{a}}$ & $60.5 \pm 12.2^{\mathrm{a}}$ & $37.4 \pm 9.4^{a}$ \\
\hline Age of males (years) & $37.3 \pm 13.8$ & $60.4 \pm 12.9$ & $36.6 \pm 8.9$ \\
\hline Age of females (years) & $45.8 \pm 15.2$ & $60.8 \pm 11.4$ & $39.2 \pm 10.3$ \\
\hline BMI $\left(\mathrm{kg} / \mathrm{m}^{2}\right)$ & $23.4 \pm 3.6^{\mathrm{a}}$ & $27.6 \pm 4.3^{\mathrm{a}}$ & - \\
\hline Duration of diabetes (years) & $11.9 \pm 11.2^{\mathrm{a}}$ & $7.8 \pm 6.7^{\mathrm{a}}$ & - \\
\hline
\end{tabular}

${ }^{a} p<0.001$ (ANOVA)

A variety of other genetic and non-genetic factors beside the size variation at the apo(a) gene locus have been described which also effect plasma Lp(a) levels. These include defective alleles at the LDL-receptor gene [23], acute-phase reactions [24], or hormones [25]. Lp(a) levels may also be significantly elevated secondary to diseases with known increased risk for atherosclerosis (e.g. renal diseases) and might therefore in part explain this increased risk.

In order to investigate the role of $\operatorname{Lp}(\mathrm{a})$ as a possible risk factor for atherosclerotic complications in diabetes, we measured $\mathrm{Lp}(\mathrm{a})$ plasma concentrations and apo(a) phenotype frequencies in two ethnically different European populations of diabetic patients and compared them with a control group.

\section{Subjects, materials and methods}

The study populations consisted of 135 patients with Type 1 (insulindependent) diabetes receiving insulin therapy and 156 patients with Type 2 (non-insulin-dependent) diabetes with no insulin treatment. All patients were free of liver and renal diseases as ascertained by routine measurement of liver enzymes (GOT, GPT, $\gamma \mathrm{GT}$ ), creatinine and urea in plasma. However, patients urine was not checked for microalbuminuria. Fasting EDTA blood samples from patients were obtained from three out-patient clinics (one in Innsbruck, two in Budapest). Non-fasting blood samples were randomly obtained from blood donors at the blood banks in Innsbruck (Austria) and Budapest (Hungary). Plasma was obtained by low-speed centrifugation and stored at $-20^{\circ} \mathrm{C}$ for a maximum of 6 months until further use. The plasma samples from Hungarian patients and control subjects were transported to Innsbruck on dry ice.

\section{Hungarian group}

Table 1 lists the characteristics of the Hungarian diabetic patients and the control group. The sex ratio was about $1: 1$ for diabetic patients, whereas the control group contained about two times as many men. According to disease type, the age of patients with Type 1 diabetes was significantly lower as compared to Type 2 diabetes patients.
Type 2 diabetic patients had higher body weight and their duration of diabetes was shorter (Table 1 ). Concentrations of haemoglobin $\mathrm{A}_{1 \mathrm{c}}$ and fructosamine were identical in both diabetic groups (Table 1). Concentration of total HDL cholesterol and $\mathrm{HDL}_{2}$ fraction were significantly lower in Type 2 diabetic patients, whereas the concentration of $\mathrm{HDL}_{3}$ cholesterol in Type 1 patients was higher than in Type 2 and control groups (Table 1).

\section{Austrian group}

The clinical properties and glycaemic control of diabetic patients from Austria were comparable to those of the Hungarian patients (Table 2). The only difference was in the lipid profile: total cholesterol concentration was lower in subjects with Type 1 diabetes than in the control and Type 2 diabetes groups (Table 2). The lower plasma levels of apo AI in subjects with Type 2 diabetes corresponded with the results of HDL cholesterol concentration, which were determined only in the Hungarian diabetic patients.

Plasma concentrations of $\mathrm{Lp}(\mathrm{a})$ were determined using an ELISA exactly as previously described [26]. The "Norm Control Lp(a) Human" from Immuno AG (Vienna, Austria) served as secondary standard. Apo(a) phenotyping was performed by SDSPAGE of whole plasma samples followed by immunoblotting according to Utermann et al. [16] with some modifications [22]. Haemoglobin $\mathrm{A}_{1 \mathrm{c}}$ was measured by microcolumn chromatography, whereas fructosamine was estimated by colorimetric assay. Fasting glucose was evaluated from plasma by the glucose oxidase method and total cholesterol was analysed with a commercially available kit (Boehringer Mannheim, Mannheim, FRG). Cholesterol concentrations in $\mathrm{HDL}$ and its subfractions $\mathrm{HDL}_{2}$ and $\mathrm{HDL}_{3}$ were measured by a dual-precipitation method according to Patsch et al. [27]. LDL cholesterol was calculated using Friedewald's formula [28]. Apo AI and apo $B$ were assayed by an immunonephelometric assay (Tinaquant, Boehringer Mannheim). $\beta$-2-microglobulin was estimated with a commercially available kit from Pharmacia, Uppsala, Sweden.

\section{Statistical analysis}

Multiple linear regression was used to adjust total cholesterol, HDL cholesterol and apolipoprotein levels for the linear effects of age and sex. The equality of $\mathrm{Lp}(\mathrm{a})$ levels among diabetic and control groups was tested by the non-parametric Kruskal-Wallis test. Other 
Table 2. Lipid and lipoprotein plasma concentrations, laboratory data and clinical characterization (mean \pm SD) of Austrian subjects

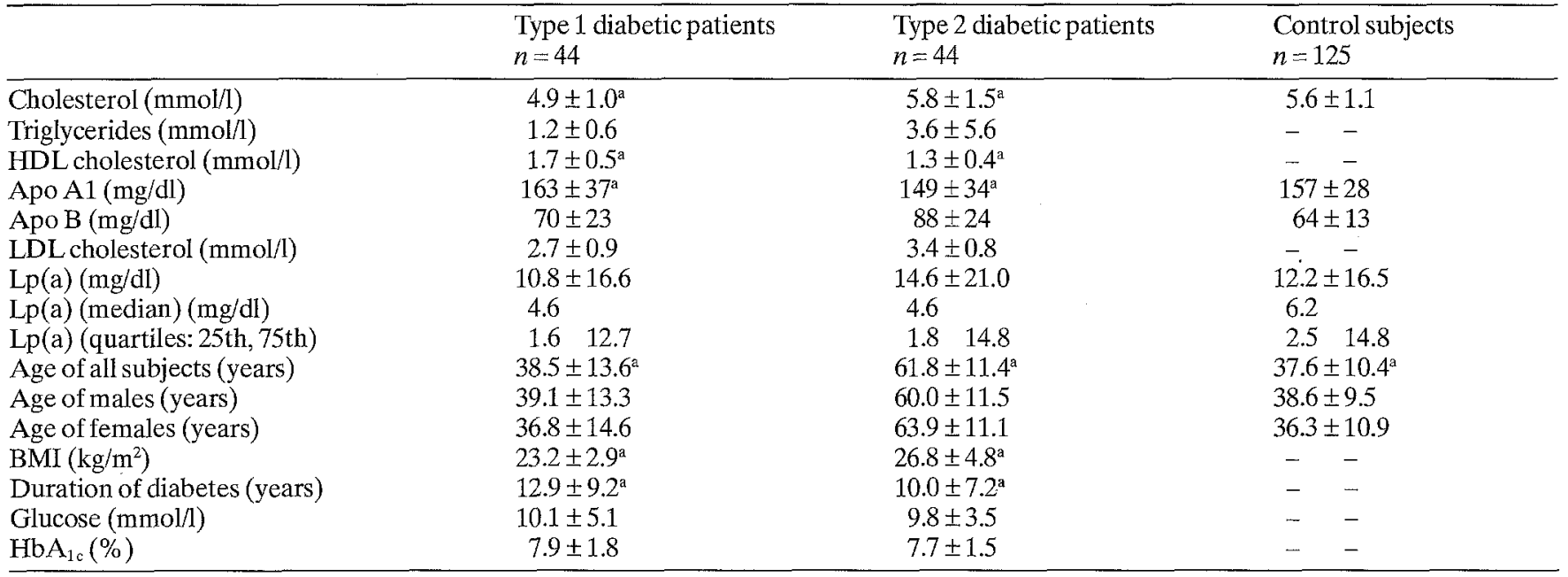

${ }^{a} p<0.001$ (ANOVA)

Table 3. Frequencies of apo(a) phenotypes and $\mathrm{Lp}(\mathrm{a})$ concentrations in Hungarian diabetic patients and control subjects

\begin{tabular}{|c|c|c|c|c|c|c|c|c|c|}
\hline \multirow[t]{2}{*}{ Phenotypes } & \multicolumn{3}{|c|}{ Type 1 diabetic patients } & \multicolumn{3}{|c|}{ Type 2 diabetic patients } & \multicolumn{3}{|c|}{ Control subjects } \\
\hline & $n$ & $\%$ & mean $\pm \mathrm{SD}$ & $n$ & $\%$ & mean $\pm \mathrm{SD}$ & $n$ & $\%$ & mean $\pm \mathrm{SD}$ \\
\hline$\overline{\mathrm{B}}$ & 1 & 1.1 & 59.0 & 1 & 0.9 & 27.0 & 2 & 1.0 & $28.5 \pm 7.0$ \\
\hline $\mathrm{S} 1$ & 1 & 1.1 & 6.6 & 1. & 0.9 & 10.1 & 4 & 2.0 & $23.0 \pm 13.8$ \\
\hline $\mathrm{S} 2$ & 16 & 17.6 & $35.3 \pm 34.6$ & 17 & 15.2 & $23.5 \pm 23.4$ & 36 & 17.8 & $19.5 \pm 22.0$ \\
\hline S3 & 18 & 19.8 & $7.7 \pm 9.6$ & 18 & 16.1 & $5.7 \pm 5.3$ & 55 & 27.2 & $8.9 \pm 10.2$ \\
\hline S4 & 18 & 19.8 & $4.6 \pm 5.4$ & 25 & 22.3 & $4.4 \pm 4.7$ & 54 & 26.7 & $6.1 \pm 5.5$ \\
\hline 0 & 12 & 13.2 & $1.1 \pm 0.9$ & 17 & 15.2 & $1.8 \pm 1.8$ & 14 & 6.9 & $1.1 \pm 1.0$ \\
\hline $\mathrm{S} 2 \mathrm{~S} 4$ & 8 & 8.8 & $3.8 \pm 2.4$ & 9 & 8.0 & $36.9 \pm 27.9$ & 9 & 4.5 & $20.8 \pm 13.6$ \\
\hline S3S4 & 12 & 13.2 & - & 18 & 16.1 & $16.0 \pm 19.6$ & 16 & 7.9 & $5.8 \pm 4.2$ \\
\hline BS4 & - & - & - & 1 & 0.9 & $38.5-$ & 1 & 0.5 & 31.0 \\
\hline Total & 91 & 100 & $12.1 \pm 20.6$ & 112 & 100 & $12.2 \pm 17.9$ & 202 & 100 & $10.5 \pm 13.5$ \\
\hline
\end{tabular}

multiple group means were compared by analysis of variance (ANOVA). For the calculation of effects of apo(a) phenotypes on $\mathrm{Lp}(\mathrm{a})$ concentrations ( $R^{2}$ statistics) the values for $\mathrm{Lp}(\mathrm{a})$ concentrations were log-transformed prior to ANOVA. Pearson's chi-square statistics was used to test the independence of the apo(a) type frequencies between the diabetic patients and the control subjects. The Statistical Package for Social Sciences (SPSS) was used.

\section{Results}

\section{Lp(a) concentrations and apo(a) phenotype distribution}

The mean $\mathrm{Lp}$ (a) concentrations in both Type 1 and Type 2 diabetic patients did not differ from those of control subjects in either the Hungarian or Austrian groups (Tables 1 and 2). $\mathrm{Lp}(\mathrm{a})$ concentration showed no significant correlation with other lipid or glycaemic parameters, including the level of $\beta$-2-microglobulin. The apo(a) phenotype frequencies are shown in Tables 3 (Hungarian) and 4 (Austrian). No significant difference in distribution was observed in the two diabetic or control groups. Average $\mathrm{Lp}$ (a) levels for each phenotype in diabetic and control subjects corresponding to the two populations are shown in detail in Tables 3 and 4. If the Hungarian and Austrian patients were pooled within their respective study groups, the mean $L p(a)$ concentration was $11.2 \pm 18.3 \mathrm{mg} / \mathrm{dl}$ in Type 1 patients, $13.1 \pm 19.2 \mathrm{mg} / \mathrm{dl}$ in Type 2 patients and $11.4 \pm 14.8 \mathrm{mg} / \mathrm{dl}$ in control subjects $(p=0.54, \mathrm{NS})$. When the apo(a) frequency distribution was calculated in these pooled groups, no significant difference was obtained as well ( $p=0.26298)$. Consistent with the previously shown inverse relationship between the molecular weight of apo(a) isoforms and $\mathrm{Lp}$ (a) levels, the effects of apo(a) alleles on $\mathrm{Lp}(\mathrm{a})$ levels were comparable in the Hungarian patients and control subjects ( $R^{2}$ values: $0.24, p<0.001$ (control subjects); $0.41, p<0.001$ (Type 1 diabetic patients); $0.36, p<0.001$ (Type 2 diabetic patients).

\section{Discussion}

Conflicting data for $\mathrm{Lp}(\mathrm{a})$ levels in diabetic patients exist in the literature. One of the earliest studies in this field did not reveal a significant difference in $\mathrm{Lp}(\mathrm{a})$ levels between diabetic patients (not differentiated for Types 1 and 2) and normal control subjects [29]. Mertz and Bürvenich [30] then reported high $L p(a)$ concentrations in diabetic patients, which were confirmed by others for diabetic patients with established nephropathy [31]. More recently, normal Lp(a) levels were reported in 
Table 4. Frequencies of apo(a) phenotypes and Lp(a) concentrations in Austrian diabetic patients and control subjects

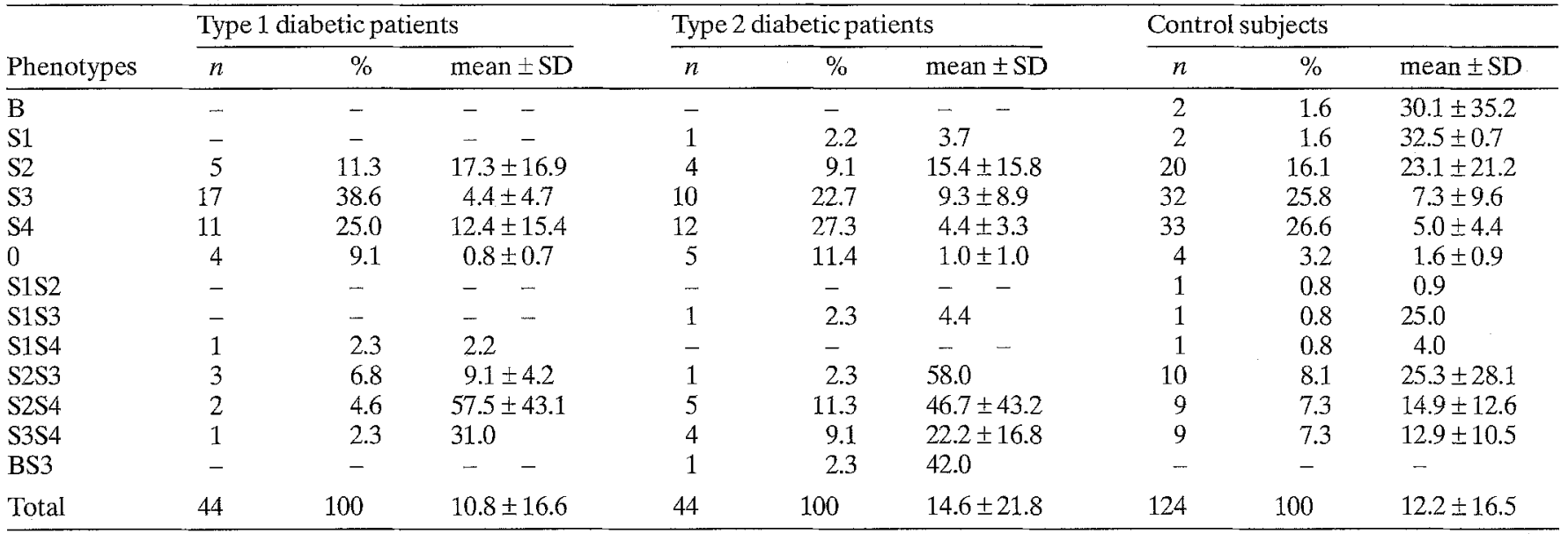

45 subjects with Type 2 diabetes [32] as well as in black children and white children with Type 1 diabetes [33]. In a small number of poorly-controlled Type 1 patients, a decline in $L p(a)$ was observed with improved glycaemic control [34]. In a similar study, $L p(a)$ levels in 12 Type 1 subjects also declined with metabolic improvement. However, the authors could not observe a correlation between the changes in glycated haemoglobin and $L p(a)$ concentration [35]. The same authors recently did not observe a change in $\mathrm{Lp}(\mathrm{a})$ concentrations with improved glycaemic control in Type 2 diabetic patients [36]. Increased $L p(a)$ values which positively correlated with $\mathrm{HbA}_{1 \mathrm{c}}$ levels were reported in ten poorly-controlled diabetic white children when compared to a control group. In contrast, no correlation of $\mathrm{Lp}$ (a) concentrations with the glycaemic status was found in the same study in black children with Type 1 diabetes [33].

In nephrotic renal disease, a correlation was reported between albuminuria and raised $\mathrm{Lp}(\mathrm{a})$ concentrations [37]. Significantly positive correlations between $L p(a)$ and urinary albumin concentrations were also shown in diabetic patients, who were not characterized in detail [31]. Elevated levels of $L p(a)$ in patients with Type 1 diabetes combined with urinary protein losses were reported by Jenkins et al. [38]. In a later study, Type 1 diabetic patients with microalbuminuria had significantly higher $L p(a)$ concentrations than those without microalbuminuria of the same sex, age, duration of diabetes and haemoglobin $A_{1 c}$ level [39]. However, a similar study failed to confirm these observations [40].

In our study the large groups of patients with both Types 1 and 2 diabetes were well controlled and Lp(a) concentrations were independent of glycated haemoglobin, fructosamine, glucose level and other lipoprotein concentrations. Most previous reports have focused on a much smaller number of patients than the present investigation. Furthermore, no apo(a) isoform analysis was performed. In small study groups, chance variation in apo(a) isoform frequencies may well account for differences between diabetic patients and control subjects.

We found no significant differences in $L p(a)$ levels among well-controlled patients with Type 1 and Type 2 diabetes and normal volunteers in two ethnically different populations. There were no differences in apo(a) phenotype frequencies between diabetic patients in our study. Thus, diabetic patients and control subjects were essentially controlled for any potential differences in $L p(a)$ concentration due to apo(a) allele frequency differences. Differences in the sex ratio between the Hungarian control and diabetic subjects are unlikely to have biased our results. Gender has no or only a moderate effect on $L p(a)$. Moreover, no significant gender difference was present in the Austrian sample. We therefore conclude that mechanisms independent of genetic apo(a) types and $L p(a)$ levels are responsible for the development of diabetic vascular complications. One additional finding of our study was that the effects of apo(a) phenotypes on $\mathrm{Lp}$ (a) levels are similar in diabetic patients and control subjects. The differences in age and sex distribution have no significance for this study since $L p(a)$ concentrations were reported to be independent of age and sex [41].

We also measured the plasma level of $\beta$-2-microglobulin as a marker for proteinuria and impaired renal function and could not find an association between $\mathrm{Lp}$ (a) and $\beta$-2-microglobulin plasma concentration in the two diabetic groups.

Atherosclerosis is the main cause of mortality in diabetic patients $[1,3]$. Lipid abnormalities and their pathophysiology in diabetes are not exactly clear [2]. One important factor contributing to atherosclerotic vascular disease in diabetes was considered to be $\mathrm{Lp}(\mathrm{a})$. In this study we demonstrate that the Lp(a) levels and apo(a) phenotype frequencies in Type 1 and Type 2 patients do not differ from those in normal control subjects from two Caucasian populations. These results suggest a rather unlikely role of $\mathrm{Lp}(\mathrm{a})$ as a risk factor contributing to atherosclerotic complications in diabetes.

Acknowledgements. The expert technical assistance of Ms. U. Scheidle, L. Fineder, G. Tröbinger, M. Kovács and L. Keszthelyi is appreciated. This study was supported by grants from the Austrian Fonds zur Förderung der wissenschaftslichen Forschung S4604 and S4610 to H.D. and G.U. and S4606 to J.R.P as well as from OTKA1072 to A. C., J. K. and L. R.. 


\section{References}

1. Garcia MJ, McNamara PM, Gordon T, Kannel WB (1974) Morbidity and mortality in diabetes in the Framingham population. Diabetes 23: 105-111

2. Kostner GM, Karádi I (1988) Lipoprotein alterations in diabetes mellitus. Diabetologia 31: 717-722

3. Howard BV (1987) Lipoprotein metabolism in diabetes mellitus. J Lipid Res 28: 613-628

4. Ganda OP (1980) Pathogenesis of macrovascular disease in the human diabetic. Diabetes 29: 931-942

5. Rhoads GG, Dahlen G, Berg K, Morton NE, Dannenberg AL (1986) $\mathrm{Lp}$ (a) lipoprotein as a risk factor for myocardial infarction. JAMA 256: 2540-2544

6. Hoefler G, Harnoncourt F, Paschke E, Mirtl W, Pfeiffer KH, Kostner GM (1988) Lipoprotein(a). A risk factor for myocardial infarction. Arteriosclerosis 8: 398-401

7. Sandholzer C, Boerwinkle E, Saha N, Tong C, Utermann G (1992) Apolipoprotein(a) phenotypes, $\mathrm{Lp}(\mathrm{a})$ concentration and plasma lipid levels in relation to coronary heart disease in a Chinese population: evidence for the role of the apo(a) gene in coronary heart disease. J Clin Invest 89: 1040-1046

8. Bihari-Varga M, Gruber E, Rotheneder M, Zechner R, Kostner GM (1988) Interactions of lipoprotein $\mathrm{Lp}$ (a) and low density lipoprotein with glycosaminoglycans from human aorta. Arteriosclerosis 8: 851-857

9. Edelberg JM, Gonzalez-Gronow M, Pizzo SV (1990) Lipoprotein(a) inhibition of plasminogen activation by tissue-type plasminogen activator. Thromb Res 57: 155-162

10. Utermann G, Weber W (1983) Protein composition of Lp(a) lipoprotein from human plasma. FEBS Lett 154:357-361

11. Gaubatz JW, Heideman C, Gotto AM Jr, Morrisett JD, Dahlen GH (1983) Human plasma lipoprotein (a): structural properties. J Biol Chem 258: 4582-4589

12. Utermann G (1989) The mysteries of lipoprotein(a). Science 246: 904-910

13. McLean JW, Tomlinson JE, Kuang W-J et al. (1987) cDNA sequence of human apolipoprotein (a) is homologous to plasminogen. Nature 300: 132-137

14. Karádi I, Kostner GM, Gries A, Nimpf J, Romics L, Malle E (1988) Lipoprotein (a) and plasminogen are immunochemically related. Biochim Biophys Acta 960:91-97

15. Kratzin H, Armstrong VW, Niehaus M, Hilschman N, Seidel D (1987) Structural relationship of an apolipoprotein (a) phenotype $(570 \mathrm{kDa})$ to plasminogen: homologous kringle domains are linked by carbohydrate-rich regions. Biol Chem HoppeSeyler 368: 1533-1544

16. Utermann G, Menzel HJ, Kraft HG, Duba HC, Kemmler HG, Seitz C (1987) Lp(a) glycoprotein phenotypes. Inheritance and relation to $\mathrm{Lp}(\mathrm{a})$-lipoprotein concentrations in plasma. J Clin Invest 80: 458-465

17. Kamboh MI, Ferrell RE, Kottke BA (1991) Expressed hypervariable polymorphism of apolipoprotein (a). Am J Hum Genet 49: 1063-1074

18. Lindahl G, Gersdorf E, Menzel HJ, Seed M, Humphries S, Utermann $G(1990)$ Variation in the size of human apolipoprotein (a) is due to a hypervariable region in the gene. Hum Genet 84:563-567

19. Lackner C, Boerwinkle E, Leffert CC, Rahmig T, Hobbs HH (1991) Molecular basis of apolipoprotein (a) isoform size heterogeneity as revealed by pulsed-field gel electrophoresis. J Clin Invest 87: 2153-2161

20. Gavish D, Azrolan N, Breslow JL (1989) Plasma Lp(a) concentration is inversely correlated with the ratio of kringle IV/kringle V encoding domains in the apo(a) gene. J Clin Invest 84:2021-2027

21. Kraft HG, Köchl S, Menzel HJ, Sandholzer C, Utermann G (1992) The apolipoprotein(a) gene-a transcribed hypervariable locus controlling plasma lipoprotein(a) concentration. Hum Genet (In press)

22. Sandholzer C, Hallman DM, Saha N et al. (1991) Effects of the apolipoprotein(a) size polymorphism on the lipoprotein(a) concentration in 7 ethnic groups. Hum Genet 86: 607-614
23. Utermann G, Hoppichler F, Dieplinger H, Seed M, Thompson $\mathrm{G}$, Boerwinkle E (1989) Defects in the LDL receptor gene affect $\mathrm{Lp}$ (a) lipoprotein levels: multiplicative interaction of two gene loci associated with premature atherosclerosis. Proc Natl Acad Sci USA 86: 4171-4174

24. Maeda S, Abe A, Seishima M, Makino K, Noma A, Kawade M (1989) Transient changes of serum lipoprotein(a) as an acute phase protein. Atherosclerosis 78: $145-150$

25. Henriksson P, Angelin B, Berglund L (1992) Hormonal regulation of serum Lp(a) levels: opposite effects after estrogen treatment and orchidectomy in males with prostatic carcinoma. J Clin Invest 89: 1166-1171

26. Menzel H-J, Dieplinger H, Lackner Cet al. (1990) Abetalipoproteinemia with an apoB-100-lipoprotein(a) glycoprotein complex in plasma. Indication for an assembly defect. J Biol Chem 265: 981-986

27. Patsch W, Brown SA, Morrisett JD, Gotto AM Jr, Patsch JR (1989) A dual-precipitation method evaluated for measurement of cholesterol in high-density lipoprotein subfractions $\mathrm{HDL}_{2}$ and $\mathrm{HDL}_{3}$ in human plasma. Clin Chem 35: 265-270

28. Friedewald WT, Levy RI, Fredrickson DS (1972) Estimation of the concentration of low-density lipoprotein cholesterol in plasma, without use of the preparative ultracentrifuge. Clin Chem 18: 499-502

29. Schernthaner G, Kostner GM, Dieplinger H, Prager R, Muehlhauser T (1983) Apolipoproteins AI, AII, B, Lp(a) and lecithin:cholesterol acyltransferase activity in diabetes mellitus. Atherosclerosis 49: 277-293

30. Mertz DP, Bürvenich K (1985) Unterschiedliche Werte von Lipoprotein $L p(a)$ bei erwachsenen Diabetikern in Abhängigkeit von der Therapieform. Klin Wochenschr 63: 648-650

31. Takegoshi T, Haba T, Hirai J et al. (1990) Alterations of lipoprotein(a) in patients with diabetic nephropathy. Atherosclerosis 83: 99-100

32. Joven J, Vilella E (1991) Serum levels of lipoprotein(a) in patients with well-controlled non-insulin-dependent diabetes mellitus. JAMA 265: 1113-1114

33. Levitsky LL, Scanu A, Gould SH (1991) Lipoprotein(a) levels in black and white children and adolescents with IDDM. Diabetes Care 14: 283-287

34. Bruckert E, Davidoff P, Grimaldi A et al. (1990) Increased serum levels of lipoprotein(a) in diabetes mellitus and their reduction with glycemic control. JAMA 263: 35-36

35. Haffner SM, Tuttle KR, Rainwater DL (1991) Decrease of lipoprotein(a) with improved glycemic control in IDDM subjects. Diabetes Care 14: 302-307

36. Haffner SM, Tuttle KR, Rainwater DL (1992) Lack of change of lipoprotein (a) concentration with improved glycemic control in subjects with type II diabetes. Metabolism 41:116-120

37. Karádi I, Romics L, Palos G et al. (1989) Lp(a) lipoprotein concentration in serum of patients with heavy proteinuria of different origin. Clin Chem 35: 2121-2123

38. Jenkins AJ, Steele JS, Janus ED, Best JD (1991) Increased plasma apolipoprotein(a) levels in IDDM patients with microalbuminuria. Diabetes 40: 787-790

39. Kapelrud H, Bangstad H-J, Dahl-Jorgensen K, Berg K, Hanssen KF (1991) Serum Lp(a) lipoprotein concentrations in insulin dependent diabetic patients with microalbuminuria. Br Med J 303: 675-678

40. O'Donnell MJ, Bain SC, Barnett AH, Jones A (1991) Lp(a) concentrations. Br Med J 303: 1134

41. Albers JJ, Hazzard WR (1974) Immunochemical quantification of human plasma $L p(a)$ lipoprotein. Lipids 9: 15-26

Received: 9 June 1992

and in revised form: 7 September 1992

Prof. Dr. G. Utermann

Institute of Medical Biology and Human Genetics

University of Innsbruck

Schoepfstrasse 41

A-6020 Innsbruck, Austria 